\title{
Biological control program is being developed for brown marmorated stink bug
}

by Jesus Lara, Charlie Pickett, Chuck Ingels, David R. Haviland, Elizabeth Grafton-Cardwell, David Doll, James Bethke, Ben Faber, Surendra K. Dara

and Mark Hoddle

\section{Brown marmorated stink bug (BMSB) is an invasive, polyphagous pest that has been} detected in 42 U.S. states. In 2010, it caused millions of dollars in crop damages to apple growers on the East Coast, where it arrived from Asia during the 1990s. In 2002, BMSB was reported in California; since then, it has been detected in 28 counties and is established in at least nine counties. Although this pest has not yet been found on commercial crops in the state, detections of BMSB in commercial orchards have been documented in Oregon and Washington. Proactive research in California has joined national efforts led by U.S. Department of Agriculture researchers to develop a classical biological control program for BMSB. A study is under way to determine potential non-target effects of a specialist egg parasitoid, Trissolcus japonicus (Hymenoptera: Platygastridae), imported from Beijing, China, part of the home range of BMSB. In addition, the role of BMSB natural enemies residing in California is being assessed. A review of the recent research outlines the possible opportunities for reducing the threat BMSB poses to California.

$\mathrm{B}$ rown marmorated stink bug (BMSB), Halyomorpha halys (Stål) (Hemiptera: Pentatomidae), has a native range that includes China, Japan, Korea and Taiwan. Its host plant range extends to more than 170 species, among which are valuable ornamentals and agricultural fruit, nut and vegetable crops (Lee et al. 2013; Rice et al. 2014). BMSB can cause direct injury to crops while using its piercing-sucking mouthparts to feed. Characterization of feeding injury to marketable crops such as surface discoloration, depressed areas, deformation or abortion of fruit bodies and internal tissue damage can vary by crop (Rice et al. 2014). BMSB was first detected in the United States in 1996 in Allentown,
Pennsylvania. Since then, BMSB has been detected in 42 U.S. states, with establishment (reproduction) confirmed in at least 26 states where nuisance and/or agricultural problems associated with its presence and ensuing economic losses to crops have been reported (NIPMC 2015).

Crop losses from BMSB and aggregations in human-made structures have been significant in the eastern United States, where BMSB first established (Rice et al. 2014). The establishment of BMSB in this region confirms its tolerance to climates outside of its home range. Field and laboratory research is needed to characterize the degree to which BMSB can tolerate temperature stresses (i.e., winter cold and summer heat) and how this may influence population dynamics in other geographic locations within the United States (Cira et al. 2016). In addition, the invasion process of BMSB in the United

Online: http://californiaagriculture.ucanr.edu/ landingpage.cfm?article=ca.v070n01p15\&fulltext=yes doi: 10.3733/ca.v070n01p15
BMSB adult feeding on kumquat fruit. In California, BMSB populations are found mainly in urban locales, but there is risk they will move into agricultural areas. 
States may have been facilitated by the lack of effective natural enemies and the availability of host plants. Therefore, the influence of abiotic and biotic factors may play a significant role in determining BMSB establishment in regions where this pest has arrived.

The first BMSB detection in California was recorded in 2002, and populations are now established in at least nine counties. Although current BMSB populations are largely confined to urban areas, there is risk of their movement into agricultural areas. Considering the evidence of BMSB damage from the East Coast, researchers in California recognized a need to proactively develop management strategies for BMSB in advance of potential infestations in crop production areas. Seasonal monitoring for BMSB is essential in each detection area to confirm whether populations are established, characterize their yearly phenology and update statewide distribution maps (fig. 1), all of which are needed

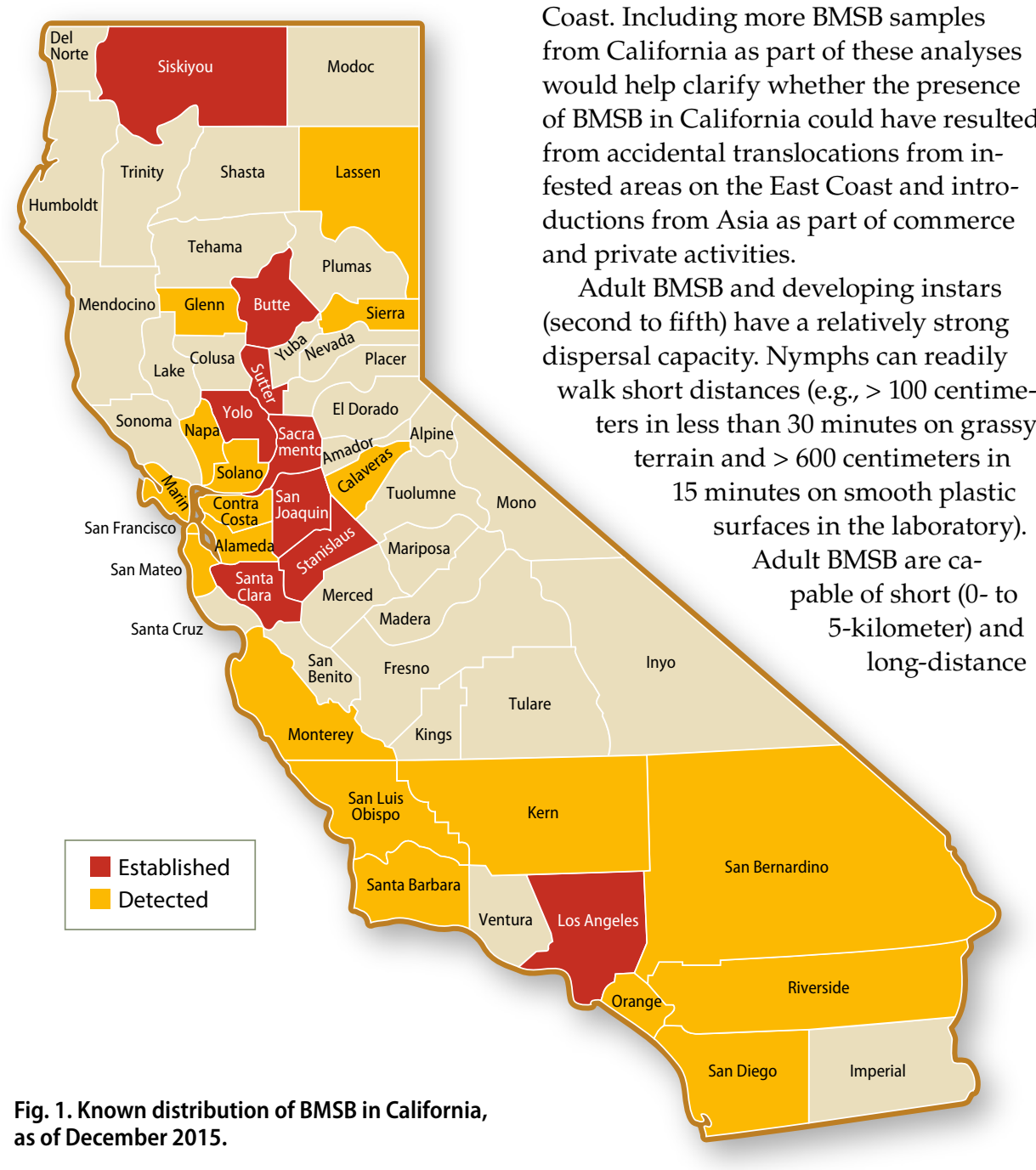

to facilitate the development of strategic BMSB management guidelines.

\section{Origin and distribution}

Initial genetic comparisons detected low diversity among BMSB populations in the United States (i.e., representative insect specimens from 10 states, including California) compared to BMSB populations in Asia and identified Beijing, China, as the likely origin of BMSB populations in the United States (Xu et

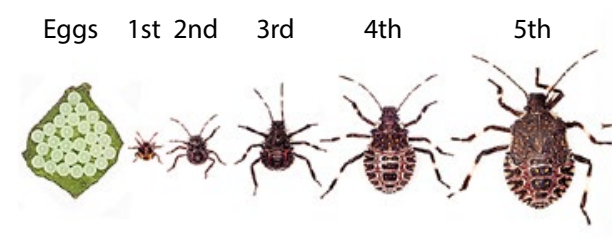
All life stages (eggs, nymphs and adults) of BMSB. al. 2014). Follow-up molecular work being led by U.S. Department of Agriculture (USDA) researchers is adding further resolution to the invasion origins of BMSB in the United States. Preliminary results suggest that there could have been multiple BMSB introductions into the West Coast compared to the East Coast. Including more BMSB samples from California as part of these analyses would help clarify whether the presence of BMSB in California could have resulted om accidental translocations from incoast and introprivate activities

Adult BMSB and developing instars (second to fifth) have a relatively strong dispersal capacity. Nymphs can readily k short distances (e.g., > 100 centimein less than 30 minutes on grassy rain and $>600$ centimeters in minutes on smooth plastic faces in the laboratory). ilt BMSB are ca5-kilometer) and long-distance
(> 5-kilometer) flights during a 24-hour period (Lee et al. 2014; Wiman et al. 2015). When disturbed, BMSB nymphs and adults hurriedly walk away, take flight (adults) or cease movement. These behaviors and the muted coloration of BMSB make it difficult to track and collect them in the environment when present at low densities. This combination of traits also suggests that BMSB can readily reach (by hitchhiking) and potentially colonize suitable new geographic areas.

In California, reproductive populations of BMSB have been known to occur in Los Angeles County since at least 2006. In fall 2013, reproductive BMSB populations were discovered in downtown Sacramento (Ingels 2014; Varela and Elkins 2011). Tracking the spread of BMSB in California has been made possible through a network of monitoring traps, with more than 100 traps deployed during 2014 and 2015 by California Department of Food and Agriculture (CDFA), UC ANR Cooperative Extension (UCCE), county agricultural commissioners and UC Riverside. In counties where BMSB populations are established, trap collections suggest there are at least one, and likely two, BMSB generations per year in some areas of California, with peak activity occurring over summer. These monitoring efforts are ongoing and will help track changes in BMSB phenology and geographic distribution in California.

Nuisance reports have been documented in Sacramento and Los Angeles counties. Aggregation behavior typically starts in late summer, with adult BMSB aggregating on outside walls as they seek refuge in garages, houses and apartment blocks, for overwintering. This behavior is troublesome not only because of the inconvenience of having to clean up bugs and remove frass stains from surfaces, but also because of the pungent cilantro-like stink BMSB produce.

\section{Growing concern}

As BMSB continues to spread to new areas in California and populations build 

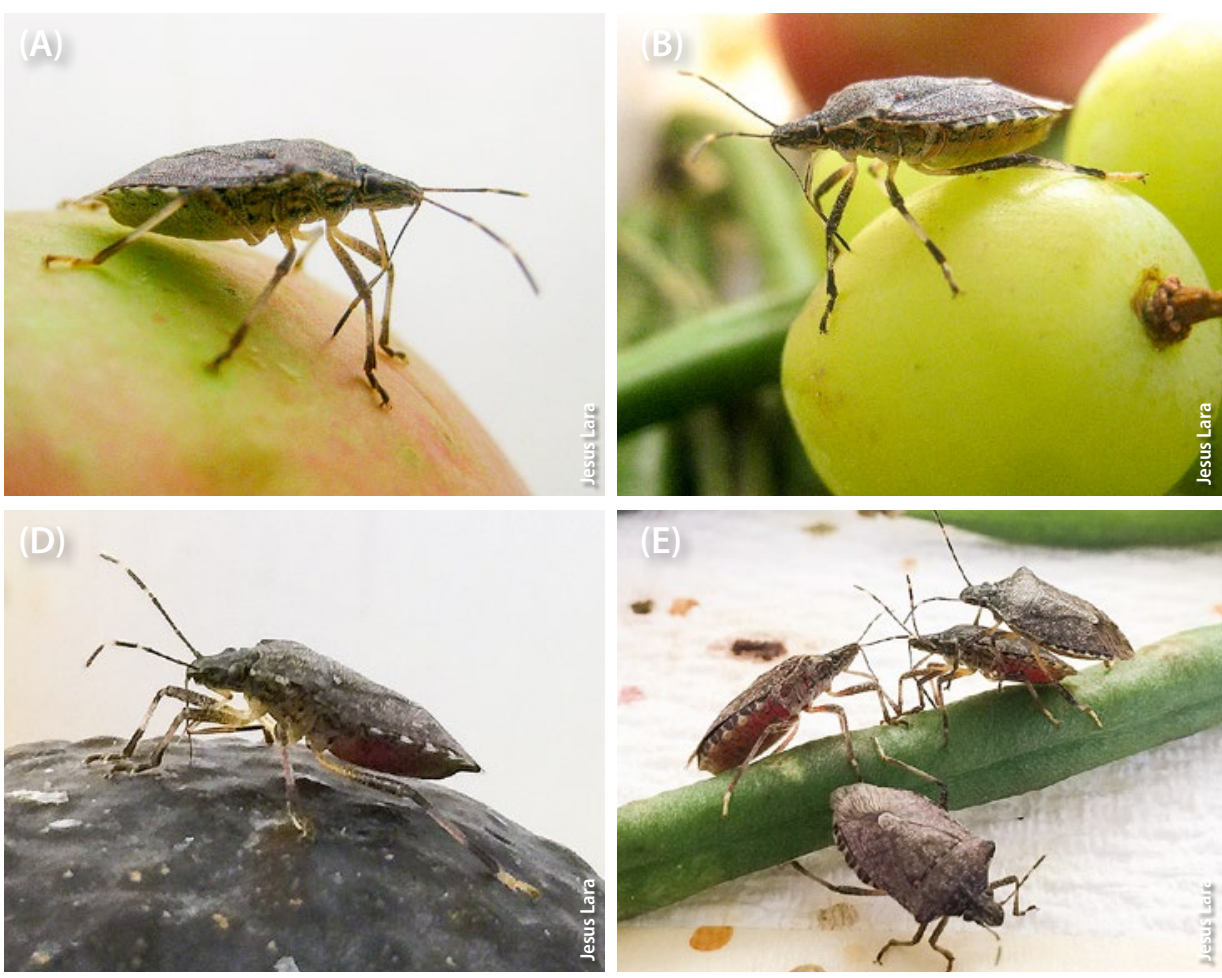

BMSB feeding on (A) apple, (B) grape, (C) pistachio, (D) Hass avocado, (E) green bean and (F) orange.

up, there is warranted concern that this polyphagous insect could become a pest on a variety of specialty crops in the state. Metcalf (1995) estimated that established invasive species cost California more than $\$ 3$ billion per year (based on $\$ 100$ per capita) in economic losses. When adjusted for inflation to 2014 dollars and population census data (USCB 2015), the cost is approximately $\$ 6$ billion. Crop damage or quarantine trade restrictions resulting

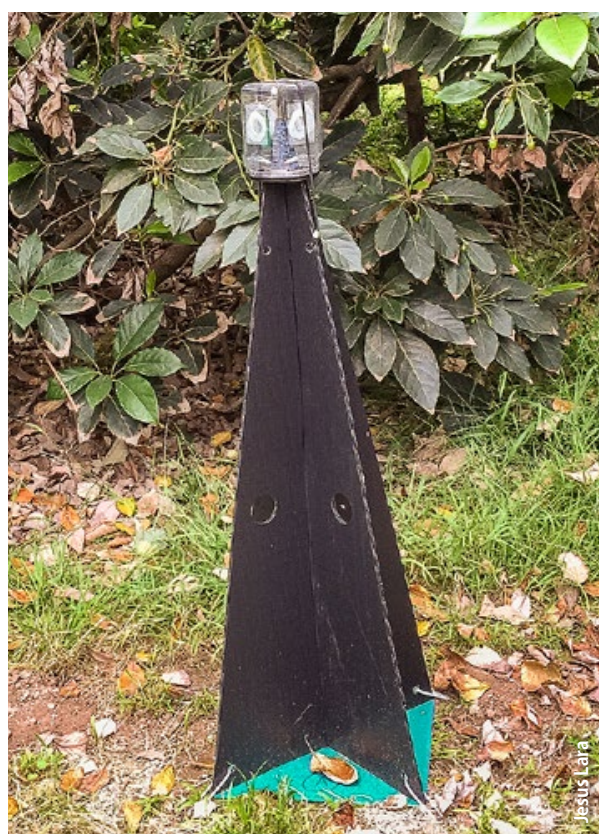

from BMSB infestations would increase the economic costs of invasive pests for California.

Nuisance problems associated with the ability of BMSB to overwinter in humanmade structures and damage attributed to BMSB feeding on crops, including apples, soybeans, tomatoes, peaches, corn, grapes and caneberries, have been documented in East Coast states (e.g., Delaware, Maryland, New Jersey, New York, Pennsylvania, Virginia and West Virginia) (Jentsch 2012; Leskey et al. 2012; Nielsen and Hamilton 2009; Pfeiffer et al. 2012; Rice et al. 2014). The ability of BMSB to feed on a variety of crops explains the concern growers, researchers and the general public have of its potential to cause economic damage. Most notably, in 2010, apple growers in Mid-Atlantic states suffered an estimated \$37 million in losses due to BMSB damage (Leskey et al. 2012). As a result, pesticide applications for BMSB control increased, in some cases as much as fourfold. Some of these pesticides have broad-spectrum activity (e.g., pyrethroids, neonicotinoids) for insects and can be harmful to natural enemies (Leskey et al. 2012; NIPMC 2014; Rice et

A BMSB pheromone-based monitoring trap set up in Los Angeles County.
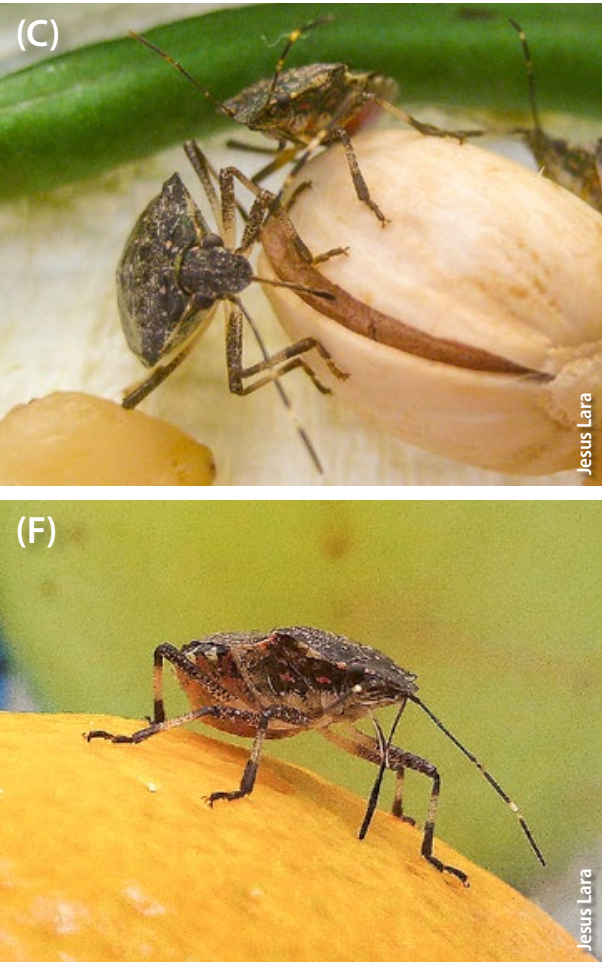

al. 2014). Increased use of these pesticides can lead to secondary pest outbreaks and result in further economic losses. California pest management programs could be similarly disrupted by BMSB if populations spread to agricultural crops and no effective and sustainable control measures are developed.

There is a growing concern over BMSB detections in agricultural areas in Oregon on commercial crops such as hazelnuts, blackberries and wine grapes (Hansen and Mullinax 2014) and in Washington on crops such as peppers, apples, peaches, plums and cherries (Eddy 2015). These detections imply that if BMSB populations continue to grow, they could eventually have a significant economic impact on agricultural production in this part of the country. One report of economic damage by BMSB in the Pacific Northwest comes from a grower in Vancouver, Washington, who attributed losses of apple to BMSB feeding (Hansen and Mullinax 2014). Although BMSB damage to commercial agricultural crops has not been reported in California, the recovery of BMSB in fall 2014 from a monitoring trap in a Butte County kiwi orchard (E. Symmes, area IPM advisor, UCCE Butte County, personal communication) indicates that the distribution of BMSB in California is still in transition. 
Evidence of this distribution transition is being documented throughout the state (Warnert 2015). By September 2015, Siskiyou, Stanislaus and Yolo were added to the list of counties where BMSB is reproducing. In January 2016, CDFA confirmed the first detection of BMSB from trap samples collected during 2015 in Kern County, but it is not clear whether BMSB is established there; further monitoring in Kern County is planned for 2016. Establishment and detection of BMSB in several parts of the Sacramento Valley and San Joaquin Valley indicates that this pest has the potential to spread farther within California's economically important Central Valley farming region, and critical information on the types of crops that may be at risk is being documented as part of CDFA's and UCCE's monitoring efforts.

During August and September 2015, BMSB was found feeding on citrus, persimmons and apples in a Sacramento community garden. In July 2015 in Los Angeles County, BMSB nymphs were found for the first time in traps placed in close proximity to residential citrus, kiwi and avocado trees; no external signs of damage to fruit attributable to BMSB were noted at those sites, but BMSB feeding damage symptoms may take some time to appear.

The full range of damage that could result from BMSB feeding is unknown for certain California crops that could be at risk. The addition of a polyphagous species and direct fruit-feeder like BMSB could aggravate existing management

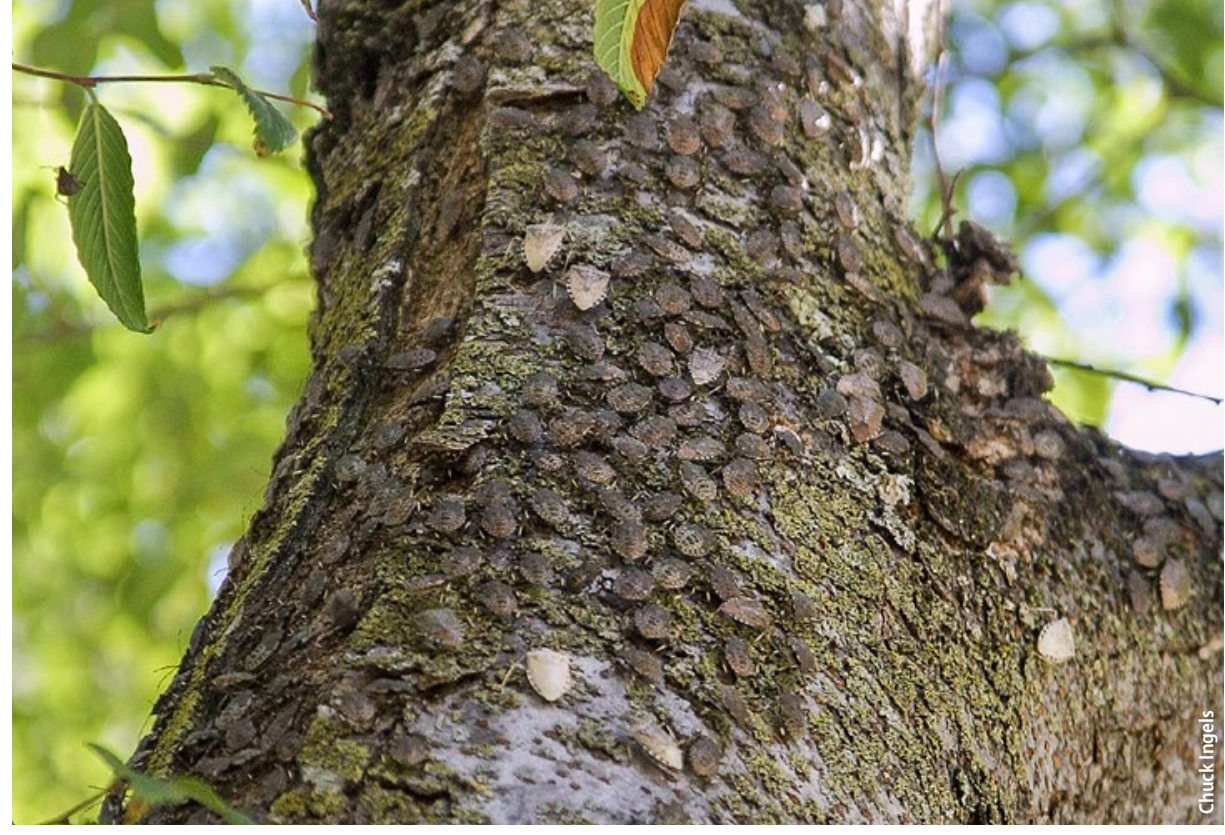

Start of BMSB adult aggregation on an elm tree during August 2015 in Sacramento County.

problems caused by other exotic species for crops like citrus (under stress from Asian citrus psyllid and huanglongbing disease) and avocado (threatened by the polyphagous shot hole borer and the fungi it vectors).

\section{Biological control research}

Field surveys in the United States (i.e., Oregon, Delaware, Maryland, Pennslyvania, Virginia) led by USDA Agricultural Research Service (ARS) and academic research institutions have documented evidence of host associations between BMSB and resident natural enemies. Several species of generalist predators (e.g., lacewings, mantids, earwigs, lady beetles, assassin bugs, minute pirate bugs, big-eyed bugs and spiders) have been observed feeding on BMSB egg masses and motile stages in the field. Field surveys also revealed there are at least 12 North American species of stink bug egg parasitoids (e.g., Anastatus spp., Gryon sp., Ooencyrtus sp., Telenomus spp. and Trissolcus spp.) in at least three families (Encyrtidae, Eupelmidae, Platygastridae) that parasitize sentinel (laboratory-sourced) BMSB egg masses deployed in the field (see Rice et al. 2014 for complete species listing).

These new host associations between BMSB and resident parasitoid species will need to be assessed experimentally for their potential to provide some level of natural BMSB control, as the presence of resident natural enemies could complement other promising BMSB biological control strategies. One of these strategies is classical biological control, under which a host-specific natural enemy from the pest's native range is reunited
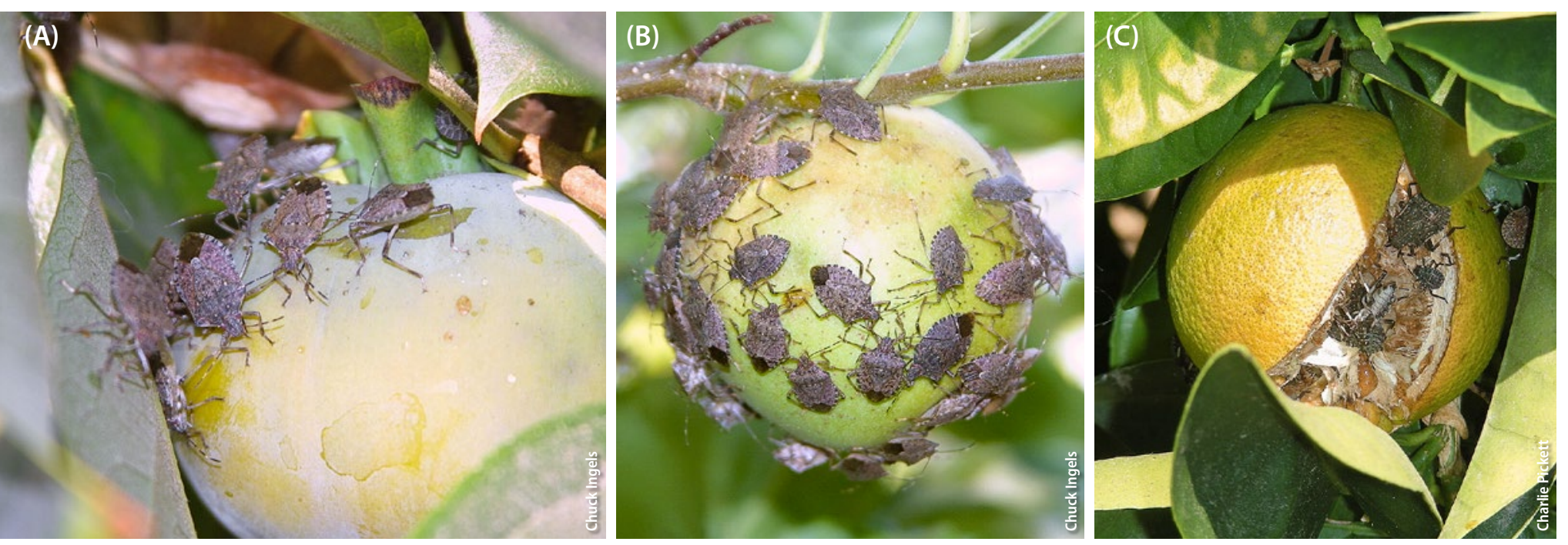

BMSB feeding on residential (A) persimmon, (B) apple and (C) citrus fruit in Sacramento County. 


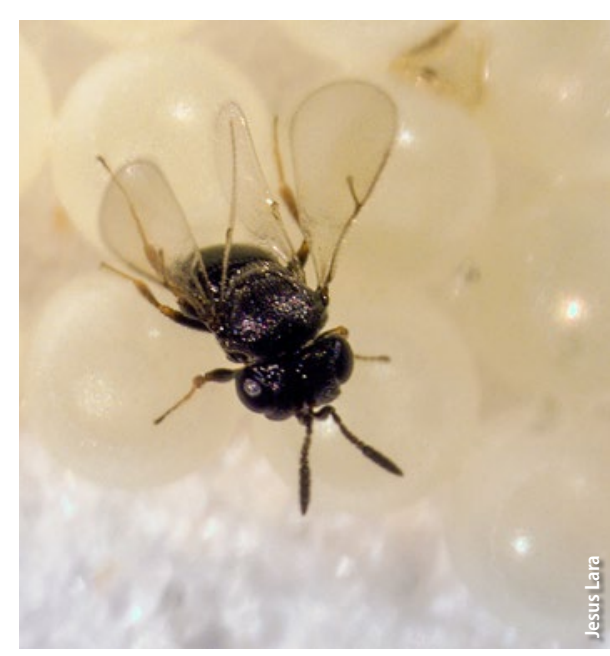

A Trissolcus japonicus female readily parasitizes eggs of BMSB in California.

with the target pest in the introduced range. To this end, Trissolcus japonicus (Ashmead) and T. cultratus (Mayr) (Hymenoptera: Platygastridae) were sourced by USDA ARS Beneficial Insects Introduction Research (ARS BIIR) from parasitized BMSB eggs in Asia. These species are under evaluation in quarantine by USDA ARS BIIR as potential candidates for classical biological control of BMSB in the United States. In Asia, levels of field parasitism of BMSB by T. japonicus have been higher than T. cultratus (Haye 2014; Talamas et al. 2013), and this observation has directed the primary focus of classical biological control research on T. japonicus.

In California, UC Riverside and CDFA have led research efforts since 2014 to determine the potential of resident (i.e., native and naturalized species) and promising foreign natural enemies (demonstrated to control BMSB in its home range but not yet released in California) for effective BMSB control. Field studies in Riverside, Los Angeles and Sacramento counties have documented resident natural enemies in California attacking BMSB egg masses, suggesting they may be useful for future management programs. Beginning in 2014, research at UC Riverside focused on assessing the risk $T$. japonicus poses to native stink bugs, some of them beneficial predators such as the predatory stink bug Podisus maculiventris (Say). This nascent classical biological control program is being supported by UCCE, researchers at CDFA and USDA ARS, and some commodity boards (e.g., pear, pistachio and table grape).

\section{Natural enemies}

Time-lapse photography from BMSB monitoring field sites in Sacramento supervised by CDFA in 2015 revealed that a generalist beetle, Laemostenus complanatus (Dejean) (Coleoptera: Carabidae), can feed on sentinel BMSB egg masses. $L$. complanatus is an adventive, or nonindigenous, species whose presence has been documented in Northern and Southern California (Frank and McCoy 1995; SBNHM 2014; Sokolov and Kavanaugh 2014). In Southern California, predation of sentinel BMSB egg masses has been documented in Los Angeles County by UC Riverside researchers; time-lapse photography is planned to determine the identity of predators.

As part of the California BMSB monitoring program, traps baited with commercially available BMSB aggregation pheromone during 2014 and 2015 also captured two specialized resident stink bug natural enemies: Euclytia flava (Townsend) (Diptera: Tachinidae), a fly that parasitizes motile stink bug life stages, and Astata spp. (Hymenoptera: Crabronidae), a wasp that attacks motile stink bug stages. E. flava specimens were captured in BMSB traps in Northern and Southern California. Astata spp. were captured from traps in Northern, Central and Southern California and species identifications are being confirmed. Currently, all Astata specimens captured in Northern California have been identified as A. occidentalis Cresson, but field observations in Sacramento demonstrate that adults of another species, $A$. unicolor Say, can attack BMSB and carry them to their nest. Rice et al. (2014) reported that Astata spp. and another parasitic fly, Trichopoda pennipes (Fabricius) (Diptera: Tachinidae), were found attacking adult

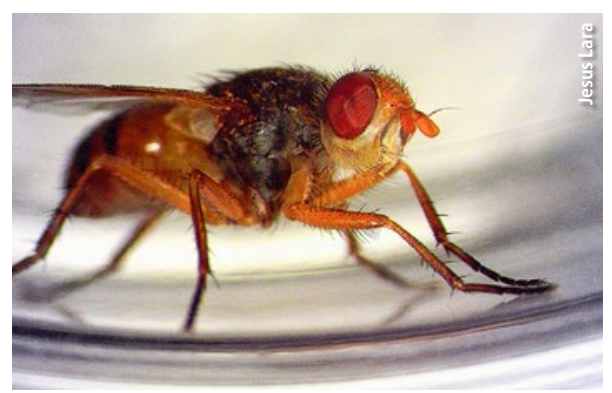

Euclytia flava, a native parasitoid of stink bugs, has been recovered from BMSB monitoring traps deployed in Los Angeles and Sacramento counties.

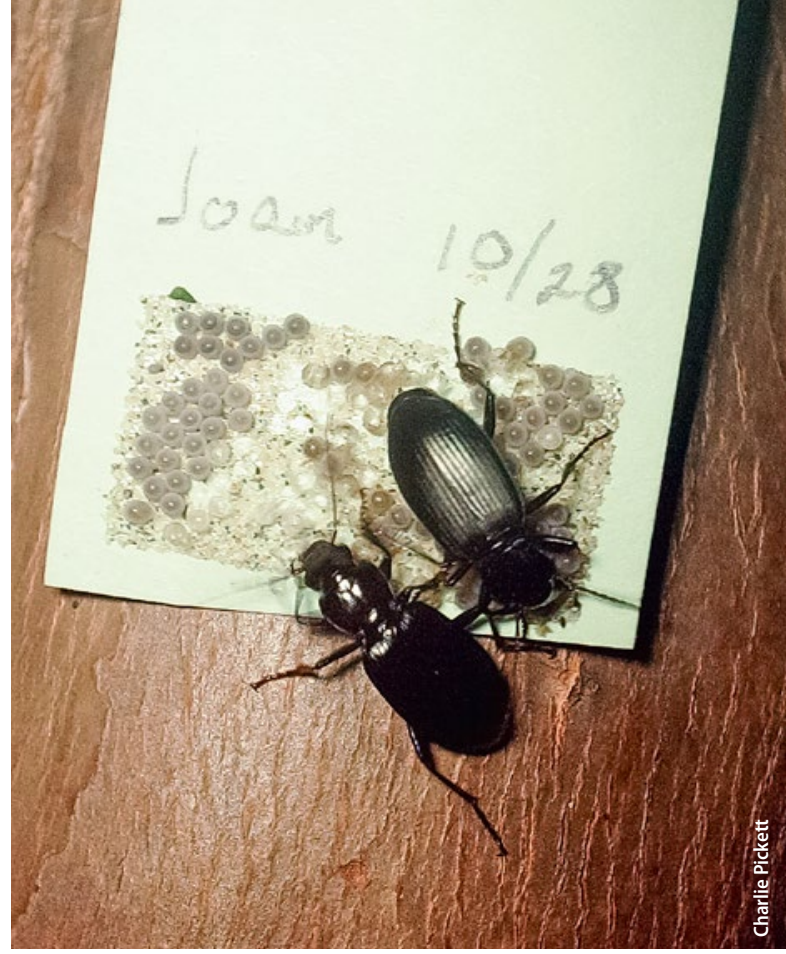

Adult Laemostenus complanatus opportunistically feed at night on sentinel BMSB eggs deployed in Sacramento County.

and late-instar BMSB life stages on the East Coast.

The impact these resident natural enemy species may have on BMSB population dynamics in California is yet to be measured and may not be sufficient to provide adequate levels of population suppression. For example, in the laboratory E. flava has been successfully reared from $P$. maculiventris adults but not from BMSB adults, even though E. flava females will lay eggs on BMSB. The contributions of other candidate resident species and their potential impacts in agricultural areas will need to be assessed as part of the emerging biological control program.

\section{Egg parasitoids}

Understanding the suitability of BMSB eggs as a host for resident stink bug egg parasitoids is important. Ideally, this

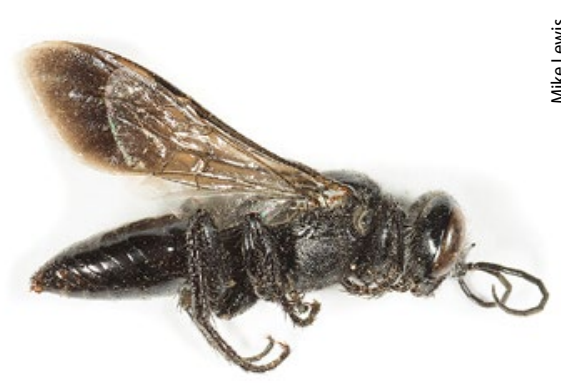

Astata species, a native predator of stink bugs, has been recovered from BMSB monitoring traps in Los Angeles and Sacramento counties and parts of the Central Valley. 
guild of natural enemies could provide some level of control if they attack the first generation of BMSB egg masses laid in the spring by female stink bugs coming out of diapause. In California, there are at least 11 reported species of stink bug egg parasitoids (table 1). Egg parasitoid activity is being monitored in Northern and Southern California by deploying sentinel BMSB egg cards; eggs are killed by freezing prior to deployment at field sites.

During spring 2015, Anastatus pearsalli Ashmead (Hymenoptera: Eupelmidae) was recovered from one of more than 100 sentinel BMSB egg masses deployed in Sacramento. To our knowledge, this is the only reported Anastatus species associated with stink bugs that occurs in this part of the state (Ehler 2000). Field data from the East Coast suggests that $A$. pearsalli parasitism levels are low (around $4 \%$ ) on BMSB eggs masses when compared to parasitism levels of another North American congener, A. reduvii (Howard), which caused 79\% BMSB egg mass parasitism at the same field study sites (Jones 2013). A. reduvii is a generalist parasitoid (Burks 1967), and its occurrence in California needs to be investigated.

In Southern California, several sentinel egg cards from more than 100 deployed in Los Angeles County from June to September 2015 were successfully parasitized by an unidentified Anastatus sp. and other platygastrid parasitoids. Successful parasitism of sentinel BMSB eggs has also been observed in Riverside County, but BMSB has not established there.

Fresh BMSB egg masses are being exposed to resident parasitoids from Northern and Southern California at the UC Riverside Insectary and Quarantine

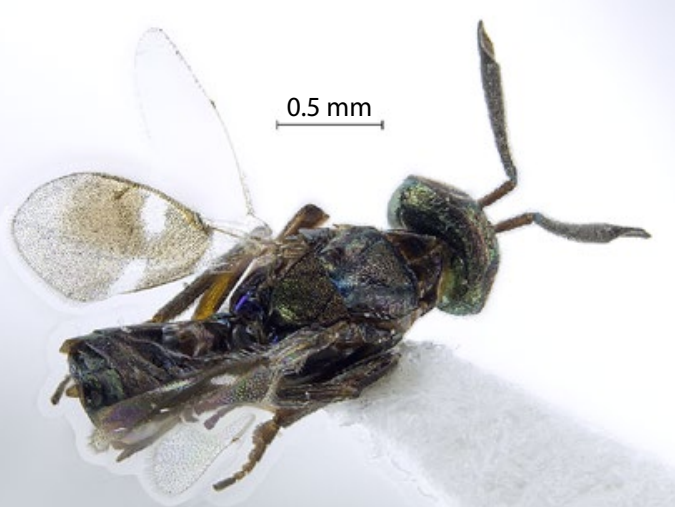

TABLE 1. Some resident stink bug egg parasitoid species (Hymenoptera) found in California

\begin{tabular}{ll}
\hline \hline Family & Species \\
\hline Encyrtidae & Ooencyrtus californicus \\
\hline Eupelmidae & Ooencyrtus johnsoni \\
\hline Platygastridae & Gryon obesum \\
& Psix tunetanus \\
\hline & Telenomus podisi \\
\hline & Trissolcus cosmopeplae \\
\hline & Trissolcus basalis \\
\hline & Trissolcus euschisti \\
\hline & Trissolcus hullensis \\
\hline & Trissolcus utahensis \\
\hline
\end{tabular}

Source: Ehler 2000

(UCR I\&Q) facility to better assess the suitability of BMSB as a developmental host for these natural enemies. The follow-up exposure experiments are necessary because freezing BMSB eggs prior to field deployment likely disrupts their defense mechanisms and may make them easier for nonspecialist egg parasitoids to parasitize. Similar experiments were conducted by Haye et al. (2015) in Europe with BMSB and native egg parasitoids there.

The suitability of BMSB eggs for other California parasitoids reared from egg masses of resident stink bug species (e.g., Banasa sp., Cholorochora sp. and Nezara viridula) or collected from sites with BMSB pheromone traps is also being evaluated at the UCR I\&Q facility. Field-collected T. basalis (Wollaston), T. utahensis (Ashmead) and Telenomus 'near' podisi (Ashmead) have been exposed to fresh (24-hour-old) BMSB egg masses in the laboratory. $T$. basalis collected from parts of France, Italy and Spain were introduced into California during the 1980s as a classical biological control agent of another invasive stink bug, Nezara viridula (Linnaeus) (Hoffmann et al. 1991). Levels of successful parasitism of BMSB egg masses by these three candidate parasitoids are notably lower than those of T. japonicus under the same controlled conditions. Furthermore, attempts to culture strains of these three resident species from

Anastatus pearsalli, a native species known to parasitize BMSB egg masses in the United States.
California on cold-treated BMSB egg masses have not been always successful.

Together, these observations highlight the fact that some resident stink bug egg parasitoids may opportunistically exploit BMSB eggs but ultimately may not be effective for controlling BMSB. Instead, the establishment of a more host-specific BMSB egg parasitoid, like T. japonicus, as part of a classical biological control program may increase significantly parasitism of BMSB egg masses.

\section{Classical biological control}

One possible factor contributing to the growing presence of BMSB in the United States may be the absence of host-specific, coevolved natural enemies from its home range. In China, $T$. japonicus can achieve an average annual parasitism rate of $50 \%$, but rates can range from $20 \%$ to $80 \%$ during the field season (Lan-Fen 2007; Yang et al. 2009). These parasitism rates refer to the percentage of the egg mass attacked. Other stink bug parasitoids associated with BMSB egg masses in China do not achieve parasitism rates higher than $10 \%$ (Yang et al. 2009). These field data suggest that $T$. japonicus could be a promising candidate for classical biological control of BMSB in the United States. Reestablishing the trophic linkage between BMSB and T. japonicus in California at an early stage of this invasion may reduce pest densities and help mitigate nuisance and agricultural problems caused by BMSB.

Before T. japonicus can be deliberately released for BMSB control in California and other parts of the United States, the impact this egg parasitoid may have on non-target stink bug species needs to be assessed. One of the key components of parasitoid-host interactions for developing successful biological control programs is quantifying parasitism rates of parasitoid-host encounters. Consequently, a variety of safety testing protocols (e.g., no-choice tests and choice tests described below) is being used to assess parasitism levels by T. japonicus on BMSB in the context of potential non-target species.

In California, T. japonicus is currently reared in quarantine at UC Riverside on BMSB egg masses. Some of the representative non-target stink bugs being reared at UC Riverside for host range safety tests include Antheminia remota (Horváth), Agonoscelis puberula Stål, Banasa sp., 
Bagrada hilaris (Burmeister), Chlorochroa uhleri (Stål), P. maculiventris, Mecidea sp., N. viridula and Thyanta sp.

Safety testing is conducted in quarantine and provides data on host use under highly artificial conditions as non-target species are exposed in vials, petri dishes or small cages to candidate natural enemies. Laboratory experimental arenas likely minimize the full range of cues natural enemies use for locating hosts and therefore facilitate determining the outcome of encounters. As part of the safety testing for $T$. japonicus, no-choice tests represent scenarios where a female T. japonicus encounters an egg mass of a single species stink bug (i.e., BMSB or a non-target species) and the parasitoid must decide whether to parasitize the host egg mass. In choice tests, T. japonicus is presented with egg masses of BMSB and at least one non-target stink bug species to elucidate its host preference.

Results from these types of tests are used to quantify level of parasitoid emergence, sex ratios, reproductive fitness of adults and other parameters that characterize the physiological host range and host specificity of T. japonicus. The physiological host range refers to the number of species that can support the successful development of $T$. japonicus and emergence of adults from parasitized eggs; host specificity refers to the degree of preference $T$. japonicus exhibits toward potential non-target species in the context of BMSB.

In addition, there are other key elements of host-parasitoid ecology influenced by the biology and ecology of each interacting species that researchers are considering when assessing and interpreting risk by an introduced natural enemy
Adult male platygastrid parasitoids, on guard, wait for future female parasitoids to emerge from a parasitized sentinel BMSB egg card (parasitism indicated by dark color of eggs) that was deployed in Los Angeles County on avocado.

to non-target species. These include the likelihood of natural encounters between T. japonicus and non-target species in the environment. For example, there may be some climatic zones that support populations of non-target species in California, but these climatic conditions may represent an establishment barrier to $T$. japonicus, thus reducing risk of attack to non-target species.

Ecological niche modeling may help delineate the potential distribution of $T$. japonicus in California and reveal areas where T. japonicus is likely to establish and how likely populations of this natural enemy will overlap with BMSB and non-target stink bug populations. Under circumstances where some risk is determined to be likely to some non-target species, a cost-benefit analysis will need to be conducted to guide the use of $T$. japonicus as a classical biological control agent of BMSB.

Safety evaluations for T. japonicus are being spearheaded at the national level by USDA ARS BIIR in Newark, Deleware, with coordinated participation from other states (e.g., California, Florida, Michigan and Oregon). This team maintains an open line of communication to design science-driven biological control programs for BMSB specific to the regions that individual members represent, and consequently, non-target stink bug species from each region are being used in safety tests with T. japonicus. Safety evaluation

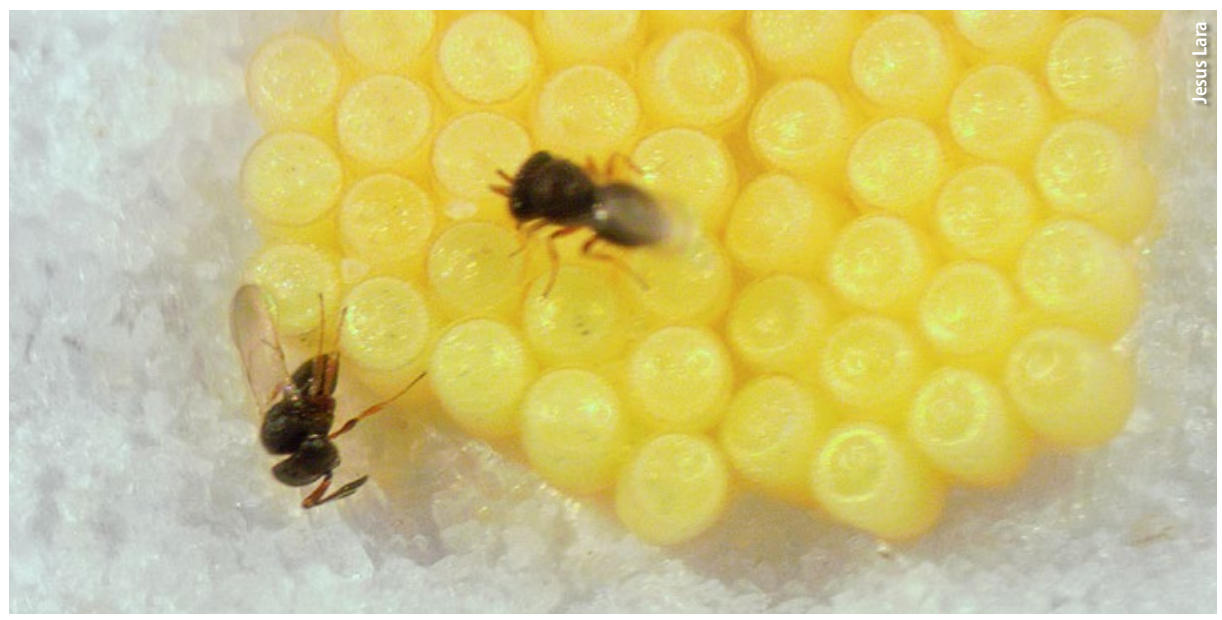

results from each team are compiled by USDA ARS BIIR to provide a better understanding of potential non-target effects of T. japonicus across the United States.

Although safety testing is still in progress, preliminary results from no-choice and choice studies at UC Riverside suggest $T$. japonicus may have a preference for BMSB egg masses over egg masses of non-target species. Additional lab experiments at Michigan State University by Botch and Delfosse (2015) are under way to provide further understanding of the ecological host range of $T$. japonicus given that added factors (i.e., the ability of the parasitoid to disperse between sites and its foraging success in different habitats) may moderate the level of interaction between T. japonicus and non-target species, thus reducing the risk to these species even further. In 2016, UC Riverside entomologists plan to follow up on this line of research on non-target stink bug species from California.

Interestingly, in fall 2014 and during 2015, field populations of T. japonicus were detected in Maryland (at three sites), Virginia (at one site) and Washington state (at one site) (HOL 2015; Talamas et al. 2015; Weiford 2015). Preliminary molecular analyses suggest that these field populations of T. japonicus were self-introduced separately on the West Coast and East Coast, possibly via parasitized BMSB egg masses on imported host plant material or hitchhiking adults entering the United

In California, the introduced egg parasitoid Trissolcus basalis parasitizes eggs of Nezara viridula (shown here) but its ability to successfully parasitize BMSB eggs is limited. 
States (Acebes et al. 2015; Hoelmer and Dieckhoff 2015).

The discovery of small populations of T. japonicus on the East Coast and West Coast does not preclude the need for California (and other states with BMSB infestations) to complete the mandatory safety tests and submit host range and host specificity data to be included in an environmental assessment report by USDA ARS. Furthermore, T. japonicus cannot be moved across state lines or purposefully released to facilitate its dispersal without USDA Animal and Plant Health Inspection Service (APHIS) approval and the appropriate permits authorizing release. In the meantime,
BMSB continues to be intercepted in counties where it may already reproduce. In November 2015, adult BMSB were intercepted in urban areas in Orange County and San Bernardino County and confirmed by entomologists at UC Riverside.

\section{Future developments}

Data from monitoring efforts and nuisance reports suggest the number of reproductive BMSB populations and their dispersal in California is increasing and this species has most likely not yet achieved its full potential geographic distribution. At this time, the location of the majority of discovered BMSB populations is limited to urban areas. In part, this may

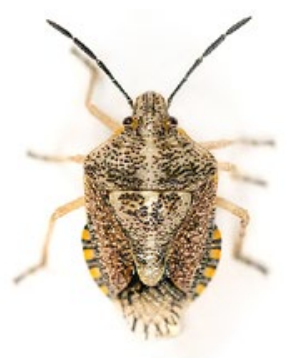

Agonoscelis

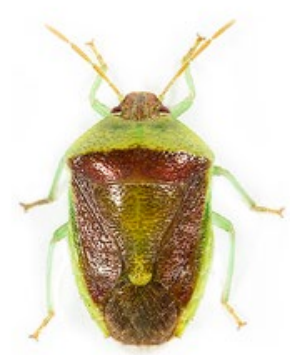

Banasa

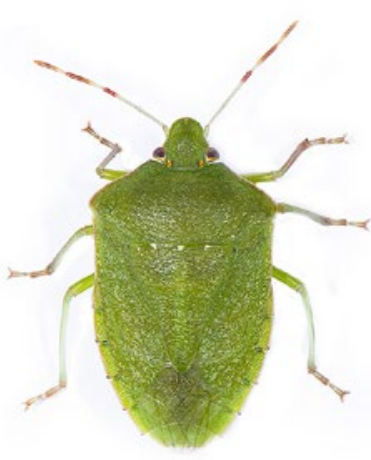

Nezara

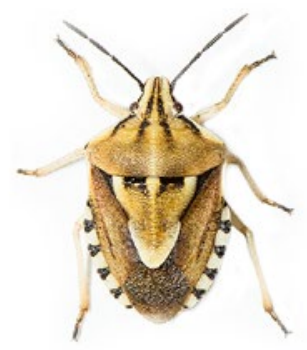

Antheminia

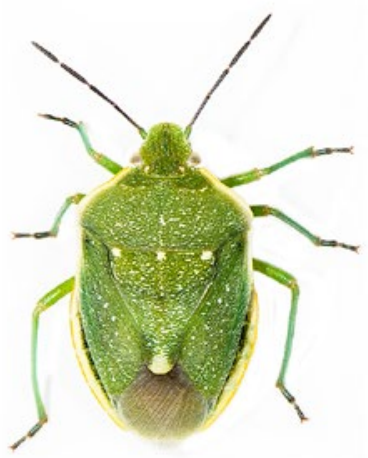

Chlorochroa

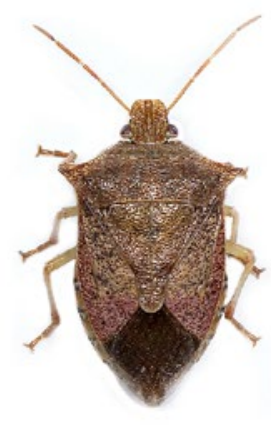

Podisus

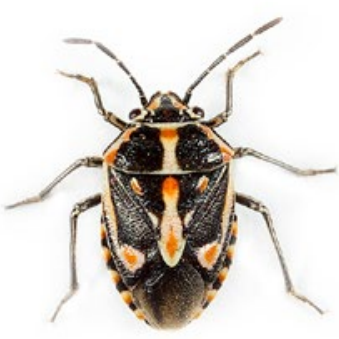

Bagrada

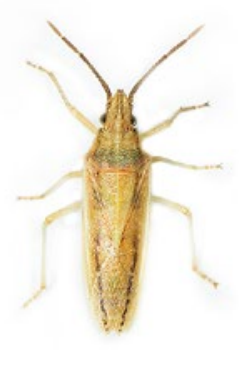

Mecidea

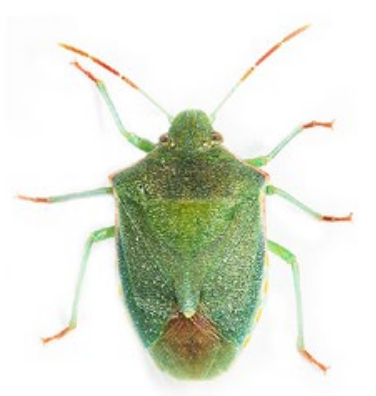

Thyanta

Some exotic and native adult stink bugs (size not to scale) from California that are being used to determine host specificity of the BMSB egg parasitoid Trissolcus japonicus.

reflect a greater likelihood of BMSB establishment success in areas with a diversity of suitable host plants, such as Chinese pistache (Pistacia chinensis), butterfly bush (Buddleja davidii) and tree of heaven (Ailanthus altissima), and an abundance of overwintering sites such as human-made structures. Urban areas may serve as yearround sources of BMSB populations; from them, adults could migrate to neighboring agricultural areas and once there establish temporary populations that damage crops (Rice et al. 2014).

It is anticipated that biological control will be an important component of a successful integrated pest management program for BMSB across various habitats (agricultural, urban and natural) where it may be difficult to implement spray programs targeting this pest as part of coordinated management efforts. Such programs would require costly, concerted efforts in searching, treating (with pesticides) and following up on the status of infestations on host plants that might harbor this pest. In this regard, biological control may be the only sustainable management solution for BMSB because stink bug parasitoids, native and introduced species, are expected to have permanent, self-sustaining populations and could naturally disperse within habitats to efficiently find existing BMSB populations on host plants. Promoting biological control to lower BMSB populations in residential areas may reduce the size of adult populations invading houses and other buildings to overwinter, and in spring, when adult reproductive diapause breaks, fewer adults migrating out of urban areas in search of host plants could lessen pest pressure in agricultural areas.

T. japonicus is a promising candidate for classical biological control of BMSB. Results of the safety testing, still in progress, will be used to petition for its future release, in conjunction with other states. A general timeline for the completion of safety tests and the permit submission and approval process is still in development and will be influenced by results of safety evaluations. T. japonicus has yet to be found or released in California, but sentinel egg cards were deployed during 2014 and 2015 by CDFA and UC Riverside to detect its possible arrival from locations within the United States or from Asia. Monitoring for T. japonicus will be expanded in California during 2016 and 
is expected to continue in other states (e.g., Delaware, Virginia, Maryland, North Carolina, Washington).

The multistate safety testing of T. japonicus is essential, as it will help guide future field studies by teams of researchers from each state (i.e., CDFA and University of California) to monitor its dispersal once it is approved for release or self-introduces, document its ecological host range and measure its economic impact on BMSB populations. In California, safety testing with $T$. japonicus at UC Riverside may take another two to three years to complete. USDA ARS BIIR will evaluate safety results from all research teams in the United States. At the same time, the results of independent field work and laboratory studies led by CDFA and UC researchers is expected to elucidate the potential of resident natural enemies to reduce BMSB populations in California. Data from these California projects will be analyzed, and in conjunction with input from USDA ARS BIIR cooperators on T. japonicus, the results will be used to formulate a biological control program for California that can be implemented in residential and agricultural areas threatened by BMSB infestations. CA

J. Lara is Postdoctoral Scholar in the Department of Entomology at UC Riverside; C. Pickett is Senior Environmental Research Scientist at California Department of Food and Agriculture, Sacramento; C. Ingels is UC ANR Cooperative Extension (UCCE) Farm Advisor in Sacramento County; D.R. Haviland is UCCE Farm Advisor in Kern County; E. Grafton-Cardwell is UCCE Entomology Specialist at UC Riverside and Director of Lindcove Research and Extension Center; D. Doll is UCCE Farm Advisor in Merced County; J. Bethke is UCCE Farm Advisor in San Diego County; B. Faber is UCCE Farm Advisor in Santa Barbara and Ventura counties; S.K. Dara is Strawberry and Vegetable Crops Advisor and Affiliated IPM Advisor in San Luis Obispo, Santa Barbara and Ventura counties; M. Hoddle is UCCE Entomology Specialist at UC Riverside.

We thank the California Department of Food and Agriculture Specialty Crop Block Grant Program, USDA Farm Bill, California Pistachio Research Board and Consolidated Central Valley Table Grape Pest and Disease Control District for financial support of BMSB biological control research. We also thank Marypat Stadtherr, Stephanie Rill, Jamie Nemecek, Minerva Gonzalez, Monty Lo, Fritz Light, Bryan Vander May, Cort Hurley, Viola Popescu, Matt Jones, Matthew Kamiyama, Gabriel Hernandez, Joshua Oliva, Vincent Jones, Jim Henrich, Tim Thibault and Dan Berry for assistance with BMSB monitoring. Special thanks to James Liebherr, Martin Hauser, Serguei Triapitsyn and Gary Gibson for assisting with insect identification.

\section{References}

Acebes A, Beers B, Bergh C, et al. 2015. Adventive populations of Trissolcus japonicus, an Asian natural enemy of Halyomorpha halys, in the USA. Poster presentation. 63rd Ann Entomol Soc of Am Meeting, Nov. 15-18, 2015. Minneapolis, MN.

Botch P, Delfosse ES. 2015. An endoparasitic egg hunt. Does habitat complexity mediate attack by Trissolcus japonicus (Hymenoptera: Platygastridae) on non-target stink bugs? Poster presentation. 63rd Ann Entomol Soc of Am Meeting, Nov. 15-18, 2015. Minneapolis, MN.

Burks BD. 1967. The North American species of Anastatus Motschulsky (Hymenoptera, Eupelmidae). T Am Entomol Soc 93(4):423-32.

Cira TM, Venette RC, Aigner J, et al. 2016. Cold tolerance of Halyomorpha halys (Hemiptera: Pentatomidae) across geographic and temporal scales. Environ Entomol. doi:10.1093/ee/nvv220.

Eddy D. 2015. Get Ready for Brown Marmorated Stink Bug in 2015. www.growingproduce.com/fruits/apples pears/get-ready-for-brown-marmorated-stink-bug in-2015/ (accessed Sept. 1, 2015).

Ehler LE. 2000. Farmscape Ecology of Stink Bugs in Northern California. Lanham, MD: Entomological Society of America. p 59

Frank JH, McCoy ED. 1995. Precinctive insect species in Florida. Fla Entomol 78(1):21-35. doi:10.2307/3495663.

Hansen M, Mullinax TJ. 2014. Stinkbugs March on Washington. www.goodfruit.com/stinkbugs-march-onwashington/\# (accessed Sept. 1, 2015).

Haye T. 2014. Seasonal field parasitism of Halyomorpha halys and co-occurring non-target Species in China. Brown Marmorated Stink Bug Working Group Meeting, June 16, 2014. Georgetown, DE.

Haye T, Fischer S, Zhang J, Gariepy T. 2015. Can native egg parsitoids adopt the invasive brown marmorated stink bug, Halyomorpha halys (Heteroptera: Pentatomidae), in Europe? J Pest Sci 88:693-705. doi:10.1007/ s10340-015-0671-1.

Hoelmer KA, Dieckhoff C. 2015. Implementing a classical biological control program for brown marmorated stink bug. Brown Marmorated Stink Bug Working Group: Synergizing IPM Research to Deliver Solutions. 63rd Ann Entomol Soc of Am Meeting, Nov. 15-18, 2015. Minneapolis, MN.

Hoffmann MP, Davidson NA, Wilson LT, et al. 1991. Im ported wasp helps control southern green stink bug. Calif Agr 45(3):20-2.

[HOL] Hymenoptera Online. 2015. Trissolcus japonicus General Information. http://hol.osu.edu/index. html?id=3249 (accessed Sept. 1, 2015).

Ingels C. 2014. Brown marmorated stink bug update. CAPCA Adviser 17(2):42-4

Jentsch P. 2012. Brown Marmorated Stink Bug in the Hudson Valley. https://grapesandwine.cals.cornell.edu/ newsletters/appellation-cornell/2012-newsletters/issue-12 (accessed Jan. 14, 2016)

Jones AL. 2013. Indigenous Natural Enemies of the Invasive Brown Marmorated Stink Bug, Halyomorpha halys (Hemiptera: Pentatomidae). Master's thesis, Department of Entomology, University of Maryland, College Park.

Lan-Fen Q. 2007. Studies on biology of the brown marmorated stink bug Halyomorpha halys (Stål) (Hemiptera: Pentatomidae), an important pest for pome trees in China and its biological control. Ph.D. dissertation, Chinese Academy of Forestry, Beijing.

Lee DH, Nielsen AL, Leskey TC. 2014. Dispersal capacity and behavior of nymphal stages of Halyomorpha halys (Hemiptera: Pentatomidae) evaluated under laboratory and field conditions. J Insect Behav 27(5):639-51 doi:10.1007/s10905-014-9456-2.
Lee DH, Short BD, Joseph SV, et al. 2013. Review of the biology, ecology, and management of Halyomorpha halys (Hemiptera: Pentatomidae) in China, Japan, and the republic of Korea. Environ Entomol 42(4):627-41. doi:10.1603/EN13006

Leskey TC, Short BD, Butler BR, Wright SE. 2012. Impact of the invasive brown marmorated stink bug, Halyomorpha halys (Stål), in Mid-Atlantic tree fruit orchards in the United States: Case studies of commercial management. Psyche 2012. doi:10.1155/2012/535062.

Metcalf R. 1995. Invasion of California by exotic pests Calif Agr 49(1):2.

Nielsen AL, Hamilton GC. 2009. Seasonal occurrence and impact of Halyomporpha halys (Hemiptera: Pentatomidae) in tree fruit. J Econ Entomol 102(3):1133-40. doi:10.1603/029.102.0335

[NIPMC] Northeastern IPM Center. 2014. Chemical Controls. www.stopbmsb.org/managing-bmsb/chemicalcontrols/ (accessed Sept. 15, 2015).

NIPMC. 2015. BMSB State-by-State Map. www. stopbmsb.org/where-is-bmsb/state-by-state/ (accessed July 15, 2015).

Pfeiffer DG, Leskey TC, Burrack HJ. 2012. Threatening the harvest: The threat from three invasive insects in late season vineyards. In: Bostanian NJ, Vincent C, Isaacs $\mathrm{R}$ (eds.). Arthropod Management in Vineyards: Pests, Approaches and Future Directions. New York: Springer. $p$ 449-74. doi:10.1007/978-94-007-4032-7_19.

Rice KB, Bergh CJ, Bergmann EJ, et al. 2014. Biology, ecology, and management of brown marmorated stink bug (Hemiptera: Pentatomidae). J Integ Pest Manage 5(3):A1-13. doi:10.1603/IPM14002.

[SBNHM] Santa Barbara Natural History Museum. 2014 The California Beetle Database. www.sbcollections.org/ cbp/cbpdatabase1.aspx (accessed April 18, 2015).

Sokolov IM, Kavanaugh DH. 2014. New records of adventive Carabidae (Coleoptera) found in California. PanPac Entomol 90(2):66-71. doi:10.3956/2014-90.2.66.

Talamas EJ, Herlihy MV, Dieckhoff C, et al. 2015. Trissolcus japonicus (Ashmead) (Hymenoptera: Scelionidae) emerges in North America. J Hymenopt Res 43:119-28. doi:10.3897/JHR.43.4661.

[USCB] United States Census Bureau. 2015. Annual Estimates of the Resident Population: April 1, 2010, to July 1, 2014. factfinder.census.gov/faces/nav/jsf/pages/ index.xhtml (accessed Sept. 1, 2015).

Varela LG, Elkins RB. 2011. New pest threat in orchards - Brown marmorated stink bug. CAPCA Adviser $15 \cdot 32-3$

Warnert J. 2015. Brown Marmorated Stink Bug Found in Stanislaus County. ucanr.edu/blogs/blogcore/postdetail. cfm?postnum=18597 (accessed Aug. 28, 2015).

Weiford L. 2015. New'Alien'Wasp Discovered in Washington State. news.wsu.edu/2015/10/22/new-alienwasp-discovered-in-washington-state/\#.VkUsmnarSUk (accessed Nov. 12, 2015).

Wiman NG, Walton VM, Shearer PW, et al. 2015. Factors affecting flight capacity of brown marmorated stink bug, Halyomorpha halys (Hemiptera: Pentatomidae). J Pest Sci 88(1):37-47. doi:10.1007/s10340-014-0582-6.

Xu J, Fonseca DM, Hamilton GC, et al. 2014. Tracing the origin of US brown marmorated stink bugs, Halyomorpha halys. Biol Invasions 16(1):153-66. doi:10.1007/ s10530-013-0510-3.

Yang ZQ, Yao YX, Qiu LF, Li ZX. 2009. A new species of Trissolcus (Hymenoptera: Scelionidae) parasitizing eggs of Halyomorpha halys (Heteroptera: Pentatomidae) in China with comments on its biology. Ann Entomol Soc Am 102(1):39-47. doi:10.1603/008.102.0104. 